\title{
BILE DUCT INJURY: CLINICAL PRESENTATION AND MANAGEMENT
}

\author{
HAKIM HAN $^{1}$, ALI M ${ }^{2}$, KHAN AS ${ }^{3}$, BHOWMIK B ${ }^{4}$, ALAM KZ ${ }^{5}$, RABBI H ${ }^{6}$, HAQUE AHMA ${ }^{7}$, ISLAM \\ $\mathrm{MN}^{8}$, SHAHJADI $\mathrm{S}^{9}$
}

\begin{abstract}
Background: Iatrogenic bile duct injury affects the patient physically, mentally, socially and financially. Bile duct injury always presents with significant symptoms and causes serious complications. Iatrogenic bile duct injury remains a considerable surgical challenge. The aim of my study was to evaluate the patients with iatrogenic bile duct injuries regarding their mode of presentation, nature and pattern of injury, to develop strategy for proper assessment, method of diagnosis and to find out the steps of safe management of these patients.
\end{abstract}

Methods: This study was carried out from January 2004 to December 2008, in the Department of Hepatobiliarypancreatic Surgery of BIRDEM Hospital, Dhaka. A total number of forty patients with iatrogenic bile duct injury were included in the study. The patients with iatrogenic bile duct injury who were managed surgically were selected randomly in my study irrespective of age, sex and status of diabetics. The patients were diagnosed with details history, proper clinical examinations and appropriate investigations.

Results: In the study the highest number of both male \& females are in the age group of 4150 , followed by 31-40 yrs age group and females were predominating in each age group. Most of the patients presented with obstructive jaundice (60\%) or biliary fistula (50\%). The highest number of injuries occurred during laparoscopic cholecystectomy (50\%). Most of the patients (60\%) presented within 1 month of initial surgery. Most of the cases were Bismuth grade 2 (35\%), grade 3 (45\%) and grade 4 (10\%). Roux-en-Y hepaticojejunostomy was done in 30 patients (75\%). After follow up of about 3 years 10 patients complained of recurrent cholangitis. 2 patients came with re-stricture and 2 patient came with secondary biliary cirrhosis.

Conclusion: All-out efforts should be taken to prevent the incidence of bile duct injury \& manage this situation if it happens. Combination of technical skill, experience and a thorough knowledge of the normal biliary anatomy and its variations can prevent or minimize the incidence of bile duct injury.

Key words: Bile duct injury, Laparoscopic cholecystectomy, Roux-en-Y hepaticojejunostomy.

J Dhaka Med Coll. 2011; 20(2) : 159-167.

\section{Introduction}

Iatrogenic bile duct injury may occur during a number of abdominal procedures. Because of the great frequency with which the operation is performed cholecystectomy remains the greatest source of post operative biliary injuries ${ }^{1}$. Other procedures in the abdomen may also put biliary tract at the risk of injury, especially those involving the liver, pancreas, stomach and duodenum. The true incidence of biliary injury after these procedures is difficult to ascertain but appears to be substantially lower than after chlecystectomy. Open cholecystectomy has long been associated with a modest incidence of biliary injuries. However the advent of laparoscopic cholecystectomy has refocused attention on this issue because of the significance increase in the number of injuries ${ }^{2}$. There are several factors associated with an increased risk of bile

1. Dr. Hafiz Ahmed Nazmul Hakim, Resident Surgeon (Casualty), Dhaka Medical College Hospital, Dhaka.

2. Prof. Mohammad Ali, Department of Hepatobiliarypancreatic Surgery, BIRDEM Hospital, Dhaka.

3. Dr. Arif Salam Khan, Resident Surgeon (General), Dhaka Medical College Hospital, Dhaka.

4. Dr. Bishwajit Bhowmik, Assistant Professor, Department of Radiology \& Imaging, BSMMU, Dhaka.

5. Dr. Kazi Zana Alam, Resident Surgeon (General), Sylhet MAG Osmani Medical College Hospital, Sylhet.

6. Dr. Hashim Rabbi, Assistant Professor, Department of Hepatobiliarypancreatic Surgery, BIRDEM Hospital, Dhaka

7. Dr. Abul Hasanat Muhammad Afzalul Haque, Assistant Registrar, Department of Surgery, Dhaka Medical College Hospital, Dhaka

8. Dr. Md. Nazrul Islam, Assistant Registrar, Department of Vascular Surgery, NICVD, Dhaka.

9. Dr. Shorifa Shahjadi, Assistant Professor, Department of Physiology, MARKS Medical College, Dhaka.

Correspondence: Dr. Hafiz Ahmed Nazmul Hakim, Resident Surgeon (Casualty), Dhaka Medical College Hospital, Dhaka. Cell phone: +8801712598407, Email: n_nazmulhakim@yahoo.com 
duct injury at cholecystectomy some of which are general and some are unique to the laparoscopic approach. Ultimately however the final common path way of most injury is either a technical error or misinterpretation of the anatomy. At the beginning of era of laparoscopic surgery, bile duct injures were attributed to learning curve effect due to inadequate exprience $^{2}$. As experience with this technique grows the risk of bile duct injury might be expected to decrease. However with the increasingly liberal application of laparoscopic cholecystectomy for more complex and difficult conditions of gall bladder, high threshold for conversion and over confidence, the overall frequency of iatrogenic bile duct injury may not significantly change or may increase ${ }^{3}$. The clinical presentation depends on the different grades of bile duct injury and presence or absence of associated vascular and gastrointestinal injury. Major injuries to the bile duct are more likely to be discovered intra operatively, although the majority remain unrecognized. Improper management and repeated attempts of inadequate reconstruction may result in disastrous complications like obstructive jaundice, recurrent cholangitis, secondary biliary cirrhosis, portal hypertension and hepatic failure. Management of bile duct injury requires specialized approach in an well equipped centre. The best result are achieved through early diagnosis, clinical judgment, adequate technical expertise, the reestablishment of bilio-enteric flow with minimum number of attempts Iatrogenic bile duct injuries are important because they produce considerable morbidity and occasional mortality. Associated vascular and gastrointestinal injures have disastrous consequences. Prevention of injury to the bile duct depends on a combination of technical skill, experience and a thorough knowledge of the normal, anatomy and its variations ${ }^{4}$.

\section{Methods}

A retrospective analysis was performed on all patients referred to the Department of Hepatobiliarypancreatic Surgery of BIRDEM Hospital, Dhaka, from January 2004 to December 2008. During this period, 40 patients were referred after major LC related injuries to the biliary tree and formed the basis for this report.

The diagnosis of bile duct injury was made from history, detail clinical examination and appropriate investigations. The information regarding primary operative procedure, presenting symptoms, the type and level of biliary tract injury, diagnostic procedures, and therapeutic interventions before and after referral was obtained from patient records. The diagnostic methods to detect the level and extent of the bile duct injury as well as complications caused to other organs, the liver in particular, included endoscopic retrograde cholangiography (ERC), percutaneous transhepatic cholangiography (PTC), ultrasound examination, computed tomography and magnetic resonance imaging, liver function tests, and laparotomy.

Initial surgical management includes drainage of intra abdominal bile collection with controlled biliary fistula, ERCP with stenting of the bile duct and treatment of sepsis. A period of 3 months was allowed for the inflammation to subside and ischemia of the bile ducts to reach a final level. After control of sepsis biliary reconstruction was done by end-to-side Rouxen-Y hepaticojejunostomy, Roux-en-Y Hepaticojejunostomy with access loop, Rouxen-Y Choledochojejunostomy, Liver resection with Double/ Triple duct Roux-en-Y cholangiojejunostomy. In some cases, associated portal vein and small bowel injuries were repaired. Closed suction drains were placed adjacent to the anastomosis. All patients underwent a Trucut needle biopsy of the liver at the time of repair.

The patients were followed up in outpatient clinic for three years. The information of their condition was obtained from patient records or, if not available, by telephone interview with the patients.

The charts were reviewed and data recorded on: demographic information, date of first operation, type of injury, surgical, endoscopic, and radiologic interventions performed before referral, time to referral, diagnostic evaluation, radiologic, endoscopic and 
surgical management, duration of stenting, liver biopsies, outcome, and most recent follow-up.

\section{Results:}

The age distribution of cases of bile duct injury varied from 18 to 64 years. The youngest patient was a girl of 18 years and the oldest lady was of 65 years. Highest age incidence was in the $4^{\text {th }}$ decade (around 35\%) both in males and females. The second largest group was of the $5^{\text {th }}$ decade followed by $3^{\text {rd }}$ decade. Of all patients $75 \%$ were female. Least number of cases were in the age group of $<20$ and $>60$ years age group. Females were predominating in all the age groups. Female:Male ratio was $5: 3$. Out of 40 patients, $24(60 \%)$ cases had obstructive jaundice, 18 (45\%) cases had abdominal pain and $20(50 \%)$ cases had biliary fistula $12(30 \%)$ cases had cholangitis during admission. So, the commonest clinical presentation was obstructive jaundice, followed by biliary fistula and abdominal pain. Among 40 cases, $20(50 \%)$ resulted from Iaparoscopic cholecystectomy, $12(30 \%)$ from open cholecystectomy, 6 (15\%) during CBD exploration. The other case was during pratial gastrectomy. Out of 40 cases, in $24(60 \%)$ cases one or more attempts were taken and in 16 $(40 \%)$ cases no attempt was taken. One attempt was taken in highest number 18 (45\%) of cases, $6(15 \%)$ patients underwent more than one additional surgery or intervention. Intervention before referral included .

Out of 40 cases, 6 patients were diagnosed peroperatively. Among these 6 cases, 4were complete transection of CBD and 2 was partial transection of CBD. Most of the cases 24 (60\%) were diagnosed within 1 month, presenting with obstructive jaundice, biliary fistula, intraabdominal collection. $6(15 \%)$ patients presented between $2^{\text {nd }}$ to $6^{\text {th }}$ months and $2(5 \%)$ patients presented between $7^{\text {th }}$ to $12^{\text {th }}$ months. These $8(20 \%)$ cases presented with obstructive jaundice, recurrent cholangitis, secondary biliary cirrhosis. One patient presented 2 years after biliary injury with secondary biliary cirrhosis due to incomplete stricture of hepatic duct confluence. Out of 40 cases, USG \& Liver function tests were done in all the cases $\&$ these investigations provided valuable informations about type of jaundice, condition of the hepatic parenchyma, ductal system and intraabdominal collection. ERCP was done in 20 cases, PTC in 14 cases, CT scan 12 cases, Tubogram in 8 cases and MRCP in 10 cases. Level of injury is shown in table-VII. According to Bismuth classification, out of 40 patients, highest number of 18 patients $45 \%$ was in Bismuth Grade- 3. $2^{\text {nd }}$ largest group was Bismuth Grade- 2 consisting of 14 patients $35 \%$, followed by Bismuth Grade 2 (10\%). A small number of cases were of Bismuth Grade $1(5 \%)$ and Bismuth Grade 5 (1 case). The most commonly employed surgical procedure was Roux-en-Y Hepaticojejunostomy. Roux-n-Y Hepaticojejunostomy was performed in 30 cases $(75 \%)$ in Bismuth grade $2 \& 3$ injuries. Choledochojejunostomy was performed in 6 cases $(15 \%)$ in grade $1 \& 2$ injuries. In grade $4 \& 5$ injuries, cholangiojejunostomy with or without liver resection was done in 4 (10\%) cases. Access loop was prepared in 4 cases in association with other procedures. Controlled biliary fistula was made in $12(30 \%)$ 3 to drain abdominal collection and control infection. Portal vein repair, small bowel repair was done in 2 case each. Routine liver biopsy was taken in all 40 cases. Among 40 cases, high-level stricture was found in 24 $(66.66 \%)$ cases, Dense adhesion $\&$ fibrosis in $20(50 \%)$ cases, gross hepatomegaly $6(15 \%)$ cases each, associated vascular and bowel injury in $2(5 \%)$ cases each. These difficulties were managed accordingly. Among the complications, wound infection ranked the top position- in 10 cases. Minor bile leak occurred in $4(10 \%)$ cases, peritonitis in 2 (5\%) cases, renal impairment in $2(5 \%)$ cases. Out of 40 patients, 30 (75\%) came for follow up for a period varying from 1 month to 3 year. Recurrent cholangitis was the commonest problem encountered in $10(25 \%)$ patients, 2 patients developed secondary biliary cirrhosis, 2 patient restricture. 16 patients had no complaint. 
Table-I

Age and sex distribution of the patients $(n=40)$

\begin{tabular}{lcc}
\hline Age (years) & Male $(\%)$ & Female $(\%)$ \\
\hline Up to 20 years & 0 & $1(5 \%)$ \\
$21-30$ Years & $2(5 \%)$ & $6(15 \%)$ \\
$31-40$ Years & $4(10 \%)$ & $10(25 \%)$ \\
$41-50$ Years & $2(5 \%)$ & $8(20 \%)$ \\
$51-60$ years & $2(5 \%)$ & $2(5 \%)$ \\
Above 60 years & 0 & $2(5 \%)$ \\
\hline
\end{tabular}

Table - II

Clinical presentation of the patients $(n=40)$

\begin{tabular}{lcc}
\hline Type of presentation & $\begin{array}{c}\text { No. of } \\
\text { patients }\end{array}$ & Percentage \\
\hline Obstructive jaundice & 24 & $60 \%$ \\
Biliary fistula & 20 & $50 \%$ \\
Abdominal pain & 18 & $40 \%$ \\
Cholangitis & 12 & $30 \%$ \\
Intraabdominal collection & 10 & $25 \%$ \\
Biliary peritonitis & 8 & $20 \%$ \\
Liver cirrhosis & 2 & $5 \%$ \\
Hepatic failure & 2 & $5 \%$ \\
\hline
\end{tabular}

Table-III

Causes of biliary injury $(n=40)$

\begin{tabular}{lcc}
\hline Name of operation & $\begin{array}{c}\text { Number } \\
\text { of cases }\end{array}$ & $\begin{array}{c}\text { Percentage } \\
(\%)\end{array}$ \\
\hline Laparoscopic & 20 & $50 \%$ \\
cholecystectomy & & \\
Open Cholecystectomy & 12 & $30 \%$ \\
CBD exploration & 6 & $15 \%$ \\
Others & 2 & $10 \%$ \\
\hline
\end{tabular}

Table-IV

Number of previous attempts and interventions $(n=40)$

\begin{tabular}{lcc}
\hline Number of previous & $\begin{array}{c}\text { Number } \\
\text { of patients }\end{array}$ & $\begin{array}{c}\text { Percentag } \\
(\%)\end{array}$ \\
\hline Attempts taken & & \\
No attempt & 16 & $40 \%$ \\
One attempt & 18 & $45 \%$ \\
Two attempts & 4 & $10 \%$ \\
> Two attempts & 2 & $5 \%$ \\
\hline
\end{tabular}

Number of previous attempts taken before referral to our care are shown in table-IV.

1. Drainage of intraabdominal collection.

2. T-tube placement.

3. Direct repair.

4. Choledochoduodenostomy.

5. Choledochojejunostomy.

Table-V

Time of presentation $(n=40)$

\begin{tabular}{lcc}
\hline Time interval & $\begin{array}{c}\text { Number } \\
\text { of cases }\end{array}$ & $\begin{array}{c}\text { Percentage } \\
(\%)\end{array}$ \\
\hline Peroperative & 6 & $15 \%$ \\
$1^{\text {st }}$ month & 24 & $60 \%$ \\
$2^{\text {nd }}-6^{\text {th }}$ months & 6 & $15 \%$ \\
$7^{\text {th }}-12^{\text {th }}$ months & 2 & $5 \%$ \\
$>1$ year & 2 & $5 \%$ \\
\hline
\end{tabular}

Table-VI

Investigations performed $(n=40)$

\begin{tabular}{lcc}
\hline Name of Investigations & $\begin{array}{c}\text { Number } \\
\text { of cases }\end{array}$ & $\begin{array}{c}\text { Percentage } \\
(\%)\end{array}$ \\
\hline USG & 40 & $100 \%$ \\
Liver function test & 40 & $100 \%$ \\
ERCP & 20 & $50 \%$ \\
PTC & 14 & $35 \%$ \\
CT scan & 12 & $30 \%$ \\
MRCP & 10 & $25 \%$ \\
Tubogram & 8 & $20 \%$ \\
Fistulogram & 4 & $10 \%$ \\
Preoperative cholangiogram & 2 & $5 \%$ \\
\hline
\end{tabular}

Table-VII

Grade of injury according to bismuth classification $(n=40)$

$\overline{\text { Bismuth classifications Number Percentage }}$

\begin{tabular}{lcc} 
& of cases & (\%) \\
\hline Bismuth Grade - 1 & 2 & $5 \%$ \\
Bismuth Grade - 2 & 14 & $35 \%$ \\
Bismuth Grade - 3 & 18 & $45 \%$ \\
Bismuth Grade - 4 & 4 & $10 \%$ \\
Bismuth Grade - 5 & 2 & $5 \%$ \\
\hline
\end{tabular}


Table-VII

Single or multiple operative procedures performed in 40 patients

\begin{tabular}{lcc}
\hline Operative procedures & $\begin{array}{c}\text { Number } \\
\text { of cases }\end{array}$ & $\begin{array}{c}\text { Percentage } \\
\text { (\%) }\end{array}$ \\
\hline $\begin{array}{l}\text { Controlled biliary fistula } \\
\text { Roux-en-Y }\end{array}$ & 12 & $30 \%$ \\
$\begin{array}{l}\text { Hepaticojejunostomy } \\
\text { Roux-en-Y }\end{array}$ & $45 \%$ \\
$\begin{array}{l}\text { Hepaticojejunostomy } \\
\text { with access loop }\end{array}$ & & $10 \%$ \\
$\begin{array}{l}\text { Roux-en-Y } \\
\text { Choledochojejunostomy }\end{array}$ & 6 & $15 \%$ \\
$\begin{array}{l}\text { Liver resection with } \\
\text { Double/ Triple duct }\end{array}$ & 4 & $10 \%$ \\
$\begin{array}{l}\text { Roux-en-Y } \\
\text { cholangiojejunostomy }\end{array}$ & & \\
$\begin{array}{l}\text { Portal vein repair } \\
\text { (associated injury with } \\
\text { bile duct injury) }\end{array}$ & 2 & $3.33 \%$ \\
$\begin{array}{l}\text { Small bowel repair } \\
\text { (associated injury with } \\
\text { bile duct injury)\% }\end{array}$ & 2 & 3.33 \\
Routine liver biopsy & 40 & $100 \%$ \\
\hline
\end{tabular}

Table-IX

Difficulties encountered during operation $(n=40)$

\begin{tabular}{lcc}
\hline Difficulties & $\begin{array}{c}\text { Number } \\
\text { of cases }\end{array}$ & $\begin{array}{c}\text { Percentage } \\
(\%)\end{array}$ \\
\hline High grade stricture & 24 & $60 \%$ \\
Dense adhesion \& fibrosis & 20 & $50 \%$ \\
Sub hepatic collection & 10 & $25 \%$ \\
Gross hepatomegaly & 6 & $15 \%$ \\
Associated vascular injury & 2 & $5 \%$ \\
Associated bowel injury & 2 & $5 \%$ \\
\hline
\end{tabular}

Table-X

Post operative complications $(n=40)$

\begin{tabular}{lcc}
\hline Complication & $\begin{array}{c}\text { Number of } \\
\text { patients }\end{array}$ & $\begin{array}{c}\text { Percentage } \\
(\%)\end{array}$ \\
\hline Wound infection & 10 & $25 \%$ \\
Minor bile leak & 4 & $10 \%$ \\
Peritonitis & 2 & $5 \%$ \\
Renal impairment & 2 & $5 \% \%$ \\
Chest infection & 2 & $3.33 \%$ \\
(pneumonia) & & \\
Mortality & 0 & \\
\hline
\end{tabular}

Table-XI

Follow up results $(n=40)$

\begin{tabular}{lcc}
\hline Features & $\begin{array}{c}\text { Number of } \\
\text { cases }\end{array}$ & $\begin{array}{c}\text { Percentage } \\
(\%)\end{array}$ \\
\hline $\begin{array}{l}\text { Number of patients } \\
\text { came for follow-up }\end{array}$ & 30 & $75 \%$ \\
No complaint & 16 & $40 \%$ \\
$\begin{array}{l}\text { Recurrent cholangitis } \\
\text { Secondary biliary }\end{array}$ & 10 & $25 \%$ \\
cirrhosis & 2 & $10 \%$ \\
Restricture & 2 & $5 \%$ \\
\hline
\end{tabular}

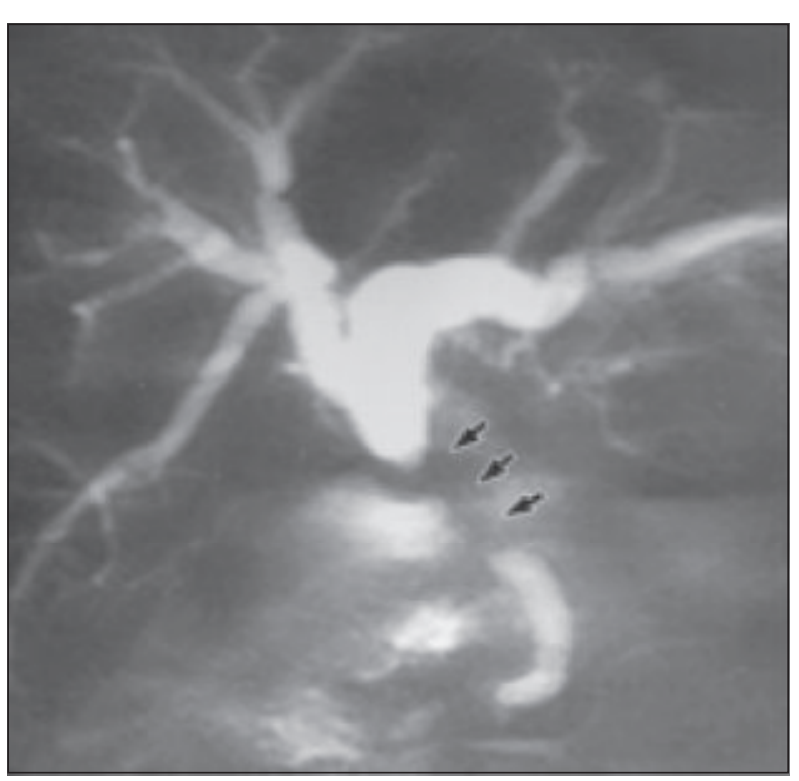

Fig.-1: ERCP shows long segment stricture in proximal common bile duct.

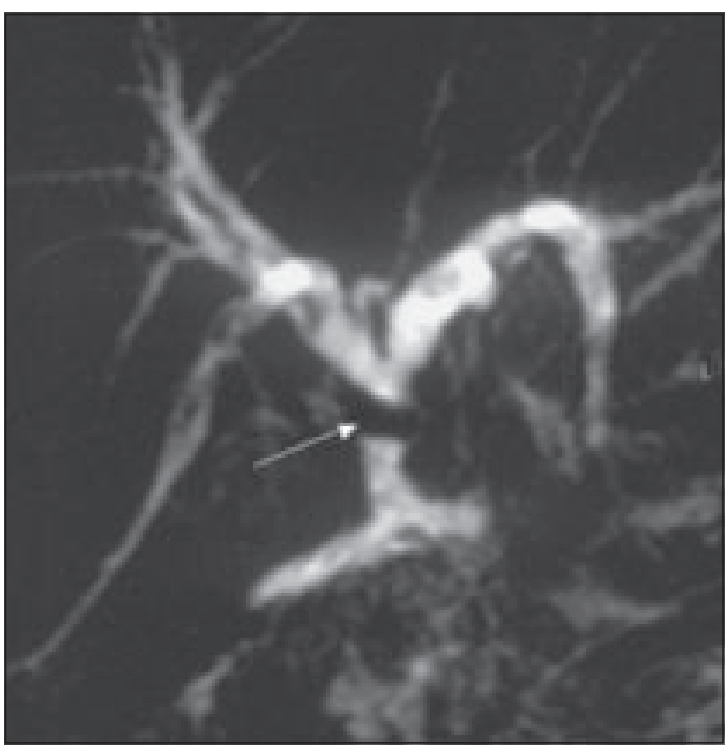

Fig.-2: $E R C P$ shows small segment stricture at proximal common bile duct. 


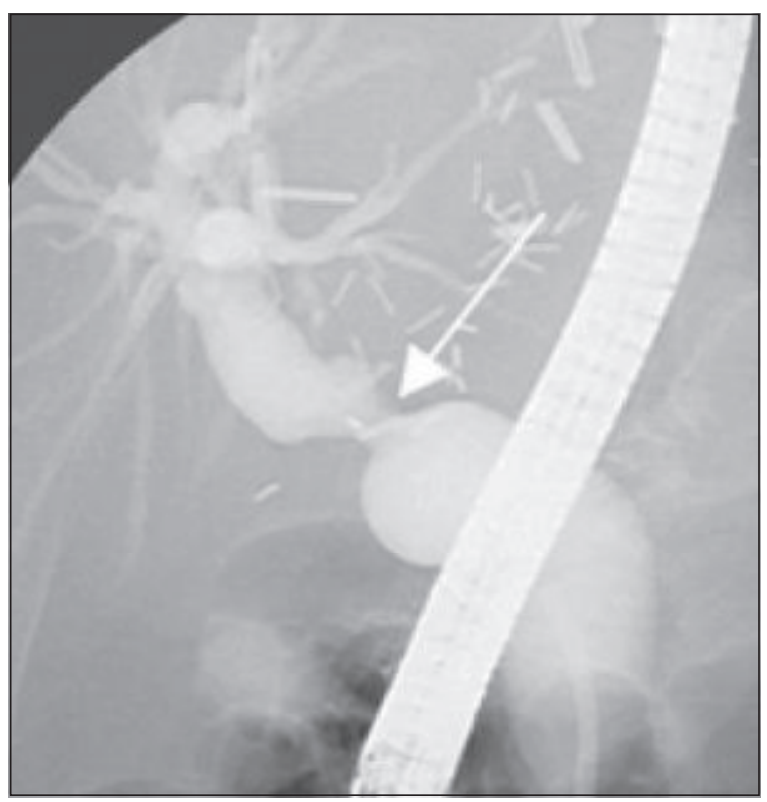

Fig.-3: ERCP shows whole length of common bile duct dilated. An incomplete stricture in mid part of common bile duct and another filling defect (calculus) at lower common bile duct.

\section{Discussion}

The exact incidence of bile duct injury in Bangladesh is not available. Injury to the biliary tree is reported in approximately $0.2 \%$ of patients undergoing open cholearstectomy ${ }^{5}$. A recent review of literature determined laparoscopic bile duct injury rate to be greater than open technique at $0.5 \%{ }^{6}$.

In the present series, the highest number of both male $\&$ females are in the age group of $41-50$, followed by $31-40$ yrs age group. Females were predominating as per sex was concerned in each age group. The finding indicates that people of young and active state especially female are the common sufferers. Thus age $\&$ sex distribution is almost similar with the study conducted by Mirza et $\mathrm{al}^{7}$. The higher incidence of injury in female is probably due to the fact that gallstone disease is more common in female. This report is consistent with report of Slater et $\mathrm{al}^{8}$.

In this study, most of the patients presented with obstructive jaundice $(60 \%)$ or biliary fistula (50\%). Other presentations were abdominal pain, cholangitis, intra abdominal collection, biliary peritonitis, liver cirrhosis and hepatic failure. A study conducted in the USA showed that most common presenting features were obstructive jaundice, bile leak and cholangitis ${ }^{9}$. Another study revealed that most common clinical presentations were obstructive jaundice (89\%) biliary fistula (30\%), biliary peritonitis $(9 \%)^{10}$. These reports are almost consistent with our study.

In our present study of 40 cases, the highest number of injuries occurred during laparoscopic cholecystectomy which is almost half of the cases. About $30 \%$ injuries were during open cholecystectomy. Acute cholecystitis was the indication for open cholecystectomy in most cases of injury. In our study, we have dealt with some biliary injuries occurring during CBD exploration \& partial gastrectomy. In a study in France, out of 22 patients of bile duct injury, 18 were during laparoscopic cholecystectomy ${ }^{11}$. This may be due to increased number laparoscopic cholecystectomy performed now a days by increasing number of surgeons. According to Mirza et $\mathrm{al}^{7}$, laparoscopic cholecystectomy is associated with a higher incidence of bile duct injury than open cholecystectomy. The operating surgeons 'learning curve' did not seem important .Residency training decreases the likelihood of injuring a bile duct, but only by decreasing the frequency of early 'Learning Curve' injuries $^{8}$. It appeared that at least one third of injuries are not related to inexperience but may reflect errors in the technique of laparoscopic cholecystectomy ${ }^{12}$. These reports are almost consistent with our study.

In the present study, 24 out of $40(60 \%)$ patients underwent one or more surgical attempts before referral. These presentations are consistent with published reports. ${ }^{13,14,15}$ Surgery before referral included drainage of intra abdominal collection, T-tube placement, direct repair, choledochoduodenostomy, choledochojejunostomy. In 16 (40\%) patients no attempt of repair, operation or intervention were taken. A study by Mirza et al showed 15 patients out of 27 underwent additional surgery before referral. In another study, in USA, 40 out of 53 patients $(75 \%)$ had one or more intervention prior to the index repair ${ }^{16}$. These reports are nearly consistent with our study. 
Interventions may vary according to availability of necessary facilities, expertise, patient's demand, condition of the patient, level of injury and presentation of the cases.

Regarding the time of presentation, in our study, most of the patients, $24(60 \%)$, presented within 1 month of surgery. Peroperatively 6 patients were referred for expert opinion. A study showed patients were transferred at a median of 26 (range 0-990) days after laparoscopic cholecystectomy although initial symptoms were noted at a median of 3 (range 0-700) days after cholecystectomy ${ }^{17}$. In a study out of 54 patients, 20 were referred immediately, 34 were referred some time after operation. So most of the patients of bile duct injury usually present in early postoperative period. In a study by Slater et $\mathrm{al}^{8}$, it was seen that more than $50 \%$ of bile duct injuries went undetected at the time of operation, 39\% of the duct injuries were recognized at the time of laparoscopic cholecystectomy. In another series, 11 out of 20 injuries were identified at the time of operation, the remainders were diagnosed at a median of 7 days (range 1-566 days) after surgery with a presentation of jaundice or abdominal pain ${ }^{18}$. All these studies were almost consistent with that of ours.

In our study we have done ultrasonogram, liver function test in all cases and ERCP, PTC, CT scan, MRCP, tubogram and fistulogram in some case to arrive at exact anatomical diagnosis. PTC proved to be more valuable than ERCP in that it defines the anatomy of the proximal biliary tree, which is necessary for biliary reconstruction. These investigations were also performed in other studies to evaluate exact site of pathology of biliary tree $1,9,10$. MRCP demonstrate the entire biliary system proximal and distal to the amputed or stenotic sites simultaneously ${ }^{19}$. According to some other study, intraoperative cholangiography is helpful for intra operative diagnosis of injuries and immediate repair ${ }^{20}$.

In our study, most of the cases were Bismuth grade $2(35 \%)$, grade $3(45 \%)$ and grade $4(10 \%)$. A study conducted in France showed Bismuth grade $1,2,3,4,5$ injuries were $15 \%, 23 \%, 25 \%$, $20 \%, 17 \%$, respectively ${ }^{44}$. Outcome was dependent on Bismuth level. The bile duct injuries that occurred at laparoscopic cholecystectomy were of greater severity than open cholecystectomy. A study by Olsan of Baptist Hospital in Nashville recently reported 117 laparoscopic bile duct injuries and found commonest type was Bismuth grade $3^{21}$. Concomitant hepatic arterial injury was identified in $12 \%$ of patients in a study ${ }^{22}$. In our study we have dealt with 1 portal vein injury and one small bowel injury. So our study coincides with that of others.

Management strategy of bile duct injury is a complex one. It varies from case to case. In our series, Roux-en-Y hepaticojejunostomy was done in 30 patients (75\%) Roux-en-Y hepateojejunostomy with access loop was done in 4 cases and Roux-en-Y Choledochojejunostomy was done in 6 cases. Liver resection with double / triple duct Roux-en-Y Cholangiojejunostomy was done in 4 cases grade 4 injuries. Controlled biliary fistula were needed to be done in 12 cases. Portal vein repair and small bowel repair was done in two case each. Liver biopsy was taken in every case to assess whether any cirrhotic change has already occurred or not. Operation time varied from 4 hours to 9 hours (average 6 hours). According to Lillemoe et al, the most commonly employed surgical procedure (85\%-90\% cases) with the best overall results is a Roux-en-Y hepatojejunostomy ${ }^{19}$. Segmental liver resection may serve an important role in the management of carefully selected patients with high grade injuries ${ }^{23}$. Definitive operation almost always a Roux-en-Y hepaticojejunostomy was required in $45 \%$ of patients in a study ${ }^{24}$. In another study, 21 out of 27 patients $(77 \%)$ underwent Roux-en-Y hepaticojejunostomy and 16 of these 21 (76.2\%) patients underwent liver biopsy ${ }^{25}$. So our study is consistent with these published reports.

In this study during repair we encountered adhesion and some difficulties as high grade stricture, gross fibrosis, sub hepatic collection, gross hepatomegaly, associated vascular \& bowel injury. These were managed accordingly. In a study, most operative difficulties were fibrosis or difficulty in delineating the anatomy 
of biliary tree ${ }^{26}$. These reports support our study.

In our series, wound infection $(25 \%)$ was the most frequent complication, followed by minor bile leak, peritonitis, renal impairment, chest infection, In our series average hospital stay was 20 days (range 15-60 days). Some reports support our study ${ }^{27}$.

In this study out of 40 patients $30(75 \%)$ came for follow up for a varying period of 1 month to 3 years. Among them 10 patients complained of recurrent cholangitis. 2 patient came with resticture and 2 patient came with secondary biliary cirrhosis. Actually secondary biliary cirrhosis developed in this patient before he presented to us. Excellent to good outcome were found in more than $50 \%$ (16 out of 30 cases). In a study, 3 out of 18 hepaticojejunostomies developed stricture subsequently, 1 patient developed intrahepatic stones and required a left segmentectomy ${ }^{28}$. In another study, 9\% patients developed subsequent anastomotic stricture and were treated with percutaneous dilatation, endoscopic dilatation and revision surgery. Excellent to good long-term results were achieved in $60 \%$ patients ${ }^{29}$. The majority of the patients treated with operative repair at an experienced center can expect good long term results with rare need for reintervention ${ }^{30}$. In another study overall success rate was $64 \%$ following definitive repair, there was one death (1.6\%) and one late structure requiring surgical revesion ${ }^{31}$.

In a study by Bauer-T-W et $\mathrm{al}^{25}$, at follow up, $62 \%$ remained asymptomatic with normal liver function test., $28 \%$ experiencing episodic cholangitis, $10 \%$ asymptomatic with persistently elevated liver enzymes. These date correspond with that of us.

Approaches to follow up in our series ranged from simple observation, measurement of liver function test, abdominal USG, MRCP. Tocchi et $\mathrm{al}^{32}$. observed that the best results correlated directly with the degree of biliary ductal dilatation. In the series $^{33}, 11$ of 22 operative failures $(50 \%)$ were successfully retreated and had satisfactory outcome, but this was substantially lower than initial repair. It has been suggested that laparoscopic bile duct injuries may have a less satisfactory outcome because of more complex nature of injuries and the frequent inflammation and fibrosis secondary to bile leakage ${ }^{34}$.

\section{Conclusion}

Iatrogenic bile duct injury remains a considerable surgical challenge. Bile duct injury always presents with significant symptoms and causes serious complications that are life threatening both in the short and the long term. Thus it causes serious health and economic problems and may expose the surgeon to expensive medico legal litigation. In addition, they increase substantially the economical burden to the patient, hospital and the community. Young and active females are common suffer of this well preventable catastrophe during operation for a benign disease.

As the surgical management of these injuries requires special multidisciplinary expertise, referral to and treatment in specialized centers offers the best chance of reversal from a potentially fatal condition to long term restoration of good health with freedom from symptoms and return to normal liver function. The best results are achieved through early diagnosis, mature clinical Judgment and technical expertise at the first attempt at repair. All-out efforts should be taken to prevent the incidence of bile duct injury and manage this situation. Combination of technical skill, experience and a thorough knowledge of the normal biliary anatomy and its variations can prevent or minimize the incidence of bile duct injury.

\section{References:}

1. Jarnagin WR, Blumgart LH. Benign biliary strictures. In: Blumgert $\mathrm{LH}$ and Fong YWB. eds. Surgery of the liver and biliary tract. $3^{\text {rd }}$ ed. Edindurgh: Saunders; 2000.

2. Strasberg SM, Hertl M, Sopper NJ. An analysis of the problem of biliary injury during laparoscopic cholecystectomy. J Am Coll Surg 1998; 180: 10125.

3. Strasberg SM, Picus DD, Drebin JA. Results of a new strategy for reconstruction of biliary injuries having an isolated right-sided component. J Gastrointest Surg 2001; 5: 266-74. 
4. Russel RCG. The gallbladder and bile ducts. In: Russel RCG, William BCS, Bulstrode CJK, eds. Bailey and Love's Short Practice of Surgery. $23^{\text {rd }}$ ed. London: Arnold; 2000.

5. Bismuth H. Postoperative strictures of the bile duct In: Blumgart LH. ed. The biliary tract. Clinical Surgery International. Edinburgh: Churchill Livingstone; 1982.

6. Abbasakoor F, Manson JM, Carr ND. Incidence and nature of bile duct injuries following laparoscopic cholecystectomy: an audit of 5913 cases. Br J Surg 1997; 84(9): 1322.

7. Mirza DF, Rossi RL, Lowell JA, Munson JL. Bile duct injury following laparoscopic cholecystectomy: Referral pattern and management. Br J Surg 1997; 84(6): 786-90.

8. Slater K, Strong RW, Wall DR, Lynch SV. Iatrogenic bile duct injury: The scourge of laparoscopic cholecystectomy. ANZ J Surg 2002; 72(2): 83-8.

9. Pellegrini CA, Thomas MJ, Way LW. Recurrent biliary stricture: patterns of recurrence and outcome of surgical therapy. Am J Surg 1984; 147: 175-80.

10. Lillemoe KD, Melton GB, Cameron JL, Pitt HA, Campbell KA, Talamini MA, et al. Postoperative bile duct strictures: management and outcome in the 1990's. Ann Surg 2000; 232: 430-41.

11. Brunt LM, Quasebarth DL, Dunnegan DL, Soper NJ. Outcomes analysis of laparoscopic cholecystectomy in the extremely elderly. Surg Endosc 2001; 15: 700-5.

12. Lillemoe KD. Benign postoperative bile duct strictures. Baillieres Clinical Gastroenterol 1997; 11: 749-79.

13. Pessaux P, Tuech JJ, Derouet N, Rouge C, Regenet N, Arnaud JP. Laparoscopic cholecystectomy in the elderly a prospective study. Surg Endosc 2000; 14: 1067-9.

14. Abdel WM, Becker JM, Connors PJ, Carr-Locke DL. Post cholecystectomy bile duct injuries: experience with 49 cases managed by different therapeutic modalities. Hepato-Gastroenterol 1996; 43:1141-7.

15. Adamsen $\mathrm{S}$, Hansen $\mathrm{OH}$, Funch-Jensen $\mathrm{P}$, Schulze S, Stage JG, Wara P. Bile duct injury during laparoscopic cholecystectomy: a prospective nationwide series. J Am Coll Surg 1997; 184: 571-8.

16. Lichtenstein $\mathrm{S}$. The role of hepatic resection in the management of bile duct injuries following laparoscopic cholecystectomy. Am Surg. 2000; 66(4): 372-6.

17. Bingener $\mathrm{J}$, Richards ML, Schwesinger WH, Strodel WE, Sirine KR. Laparoscopic cholecystectomy for elderly patient: gold standard for golden year? Arch Surg 2003; 138: 535-8.

18. Boerma D, Rauws E A, Keulemans Y C. Impaired quality of life 5 years after bile duct injury during laparoscopic cholecystectomy: a prospective analysis. Ann Surg 2001; 234(6): 750-7.
19. Lillemoe K D. Major bile duct injuries during laparoscopic cholecystectomy. Follow up after combined surgical and radiologic management. Ann Surg 1997; 225(5): 459-68.

20. Flum DR, Cheadle A, Prela C, Dellinger EP, Chan L. Bile duct injury during cholecystectomy and survival in medicare beneficiaries. JAMA 2003; 290: $2168-73$.

21. Olsen D. Bile duct injuries during laparoscopic cholecystectomy. Surg Endosc 1997; 11: 133-8.

22. Targarona EM. How, when and why bile duct injury occurs. A comparison between open and laparoscopic cholecystectomy. Surg Endosc 1998; 12(4): 322-6.

23. Vogel SB, Howard RJ, Caridi J, Hawkins IF, Jr. Evaluation of percutaneous transhepatic balloon dilatation of benign biliary strictures in high risk patients. Am J Surg 1985; 149: 73-9.

24. Goodfellow P B, Johnson A G. Laparoscopic cholecystectomy, bile duct injury and the British and Irish surgeon. Ann Royal Coll Surg Engl 1998; 80(6): 446.

25. Bauer $\mathrm{T} \mathrm{W}$. The consequences of major bile duct injury during laparoscopic cholecystectomy. J Gastrointest Surg 1998; 2(1): 61-6.

26. Flum DR, Cheadle A, Prela C, Dellinger EP, Chan L. Bile duct injury during cholecystectomy and survival in medicare beneficiaries. JAMA 2003; 290: 2168-73

27. Melton GB, Lillemoe KD, Cameron JL, Sauter PA, Coleman J, Yeo CJ. Major bile duct injuries associated with laparoscopic cholecystectomy: effect of surgical repair on quality of life. Ann Surg 2002; 235: 888-95.

28. Calvete J. Bile duct injury during laparoscopic cholecystectomy: myth or reality of the learning curve? Surg Endosc 2000; 14(7): 608-11.

29. Bussel JC. Bile duct injuries: 1989-1993; a statewide experience-Connecticut Laparoscopic Cholecystectomy Registry. Arch Surg 1996; 131(4): 382-8.

30. Kullman E, Borch K, Lindstrom E. Value of routine intraoperative cholangiography in detecting aberrant bile ducts and bile duct injuries during laparoscopic cholecystectomy. Br J Surg 1996; 83(2): 171-5.

31. Robinson TN, Rauws BA, Keulemans YC. Management of major bile duct injury associated with laparoscopic cholecystectomy. Surg Endosc 2001; 15(12): 1381-5.

32. Tocchi A, Costa G, Lepre L. The long term outcome of hepaticojejunostomy in the treatment of benign bile duct strictures. Ann Surg 1996; 224: 162-7.

33. Torkington J, Pereira J, Chalmers RT, Horner J. Laparoscopic cholecystectomy, bile duct injury and the British and Irish surgeon. Ann Royal Coll Surg Engl 1998; 80: 119-21.

34. Brooks D C, Becker J M. Management of bile leaks following laparoscopic cholecystectomy. Surg Endosc 1993; 7: 292-5. 